\title{
PENGARUH AKTIVITAS BERMAIN DAKON TERHADAP KEMAMPUAN KETANGKASAN TANGAN PASIEN CEDERA TANGAN
}

\author{
Aniek Puspitosari*1, Vincentia Nindya Christy ${ }^{2}$ \\ Poltekkes Kemenkes Surakarta Jurusan Okupasi Terapi
}

\begin{abstract}
Background: Hand injury is all kinds of trauma caused by various mechanisms that occur in the hand and can cause injury to the hand structure. One result of a hand injury is a decrease in hand dexterity. Dexterity is the speed of the hand to take or capture and place objects from one place to another so that it has an important role in daily activities. Dakon is one of the activities that can be chosen as a hand dexterity exercise. The purpose of this study was to determine the effect of dakon playing activities on the hnad dexterity abilities of patients with hnad injuries. Methods: Quantitative research using quasi experimental design. Sampling using purposive sampling technique. Data analysis using statistical tests paired sample t-test. Results: showed a significant increase in hand dexterity with a significant level of $\rho<0.05$. In the right hand the results were $0.012<0.05$, left hand $0.000<0.05$, right hand + left + second hand $0.001<0.05$ and on assembly subtest $0.014<0.05$. Conclusion: Of the study showed that playing dakon activity can improve the dexterity of the hand injured patient's hand.
\end{abstract}

Keywords: Hand Injury, Dexterity, Dakon Games

\section{PENDAHULUAN}

Tangan adalah organ yang kompleks dengan konstruksi yang rumit dan fungsi yang sangat rinci dalam anatomi fungsional (Cailliet, 1971). Sebagai organ pelaksana manusia, tangan merupakan pusat kegiatan sehari-hari baik dalam hal profesi maupun aktivitas olahraga (Voigt, 2002 dikutip oleh Schoffl et al., 2012). Tangan memiliki beberapa fungsi yang terkait dengan kegiatan hidup sehari-hari dan ekspresi. Fungsi utama tangan adalah untuk memahami, memanipulasi objek, dan menerima informasi sensorik dari lingkungan (Clarkson \& Gilewich, 1989).

Dewasa ini banyak ditemukan kasus-kasus cedera tangan di sekitar kita. Adapun penyebab cedera tangan adalah karena kecelakaan kendaraan bermotor, kecelakaan di tempat kerja, jatuh, serta terluka akibat benda tumpul dan tajam (Ihekire et al., 2010).

Cedera tangan mengakibatkan hilangnya kemampuan fungsional, penurunan lingkup gerak sendi, penurunan kekuatan otot, timbul edema, nyeri, perubahan warna kulit serta penurunan kemampuan sensorik. Kemampuan fungsional tangan meliputi grasp, pinch, manipulasi benda, fine motor skills, bilateral coordination dan dexterity (Reed, 2001). Ketangkasan tangan sangat penting dalam melakukan aktivitas sehari-hari dan digambarkan sebagai kemampuan untuk memindahkan benda dengan mudah dan terampil serta membalikkan dan menempatkan benda (Apfel, 1992 dikutip oleh Videler et al., 2008). Latihan ketangkasan tangan yang dapat dilakukan berupa aktivitas dengan gerakan jari yang perlahan dan 
teratur yang dapat mengembangkan kemampuan ketangkasan menggerakkan jari tangan, contohnya aktivitas bermain dakon (Tarigan, 2013).

\section{METODE PENELITIAN}

Desain penelitian yang digunakan dalam penelitian ini merupakan penelitian kuantitatif quasi experimental. Quasi experimental adalah penelitian yang bertujuan untuk mengevaluasi intervensi namun tidak mengambil sampel secara acak (Harris et al., 2006). Rancangan penelitian ini menggunakan pretest dan posttest dengan instrumen Purdue pegboard test. Desain ini digunakan untuk membandingkan kemampuan ketangkasan tangan pasien cedera tangan sebelum dan sesudah melakukan aktivitas bermain dakon.

\section{HASIL PENELITIAN}

Karakteristik responden yang memiliki rentang umur 40-60 tahun (dewasa pertengahan) dengan presentase sebesar $60 \%$. Sedangkan responden dengan rentang umur 21-40 tahun (dewasa awal) dan 61-80 tahun (dewasa akhir) masing-masing sebesar $20 \%$.

Karakteristik responden berdasarkan pekerjaan kebanyakan merupakan ibu rumah tangga dengan presentase sebesar 50\%. Sedangkan presentase terkecil terdapat pada sampel dengan profesi sebagai perawat, penjahit dan buruh cuci masing-masing sebesar $10 \%$.

Karakteristik responden berdasarkan sisi tangan yang terkena cedera, menunjukkan bahwa sisi tangan dekstra merupakan yang paling banyak dengan presentase sebesar $60 \%$ dikarenakan sebagian besar sampel memiliki sisi dominan kanan. 30\% sampel terkena cedera tangan pada sisi bilateral dan $10 \%$ sisanya terkena cedera pada sisi sinistra.

Hasil uji statistic dengan paired sample t-test didapatkan bahwa nilai $0.000 \quad(\rho<0.05)$ yang berarti ada perbedaan yang bermakna ketangkasan tangan setelah dilakukan tindakan permainan dakon pada pasien cedera tangan.

Pada tangan kanan didapatkan hasil $0,012<0,05$, tangan kiri $0,000<0,05$, tangan kanan + kiri + kedua tangan $0,001<0,05$ dan pada subtest assembly 0,014<0,05. Hasil penelitian menunjukkan bahwa aktivitas bermain dakon dapat meningkatkan ketangkasan tangan pasien cedera tangan.

\section{PEMBAHASAN}

Hasil penelitian menunjukkan bahwa aktivitas bermain dakon memiliki pengaruh positif bagi kemampuan ketangkasan tangan. Hasil penelitian ini didukung oleh penelitian terdahulu oleh Suciani (2012) yang menyatakan bahwa aktivitas bermain dakon dapat melatih kemampuan motorik halus, koordinasi mata tangan, termasuk ketangkasan tangan.

Hagerott (2012) dalam jurnalnya yang berjudul Effect of Game Activities on Manual Dexterity in Older Adults memaparkan bahwa pemberian aktivitas permainan dapat memberikan pengaruh positif karena meningkatkan kemampuan ketangkasan tangan pada individu dewasa yang lebih tua dengan perbedaan yang signifikan $(\rho<0,05)$.

Latihan ketangkasan tangan dalam aktivitas bermain dakon dimulai dari tahapan meraih biji dakon, menggenggam, menjatuhkan biji dakon ke setiap lubang serta melepaskan 
genggaman dari biji dakon sepenuhnya (Supriyadi, 2013).

Aktivitas bermain dakon juga dapat menjadi salah satu latihan motorik halus yang dapat dipilih karena setiap komponen gerak yang terdapat pada aktivitas bermain dakon mulai dari menggenggam biji dakon, menjatuhkan biji ke lubang sampai pada kemampuan tangan untuk melepaskan genggaman pada biji dakon membutuhkan kemampuan manipulasi motorik halus (Isnawati, 2009).

\section{KESIMPULAN DAN SARAN}

Salah satu upaya untuk meningkatkan ketangkasan tangan adalah dengan permainan dakon Permainan dakon dimainkan dengan cara memindahkan biji dakon ke lubang-lubang yang terdapat dalam papan permainan. Permainan dakon ini memiliki nilai ketangkasan tangan yang besar sehingga efektif untuk dijadikan terapi terhadap kemampuan ketangkasan tangan pasien cedera tangan

Saran yang dapat diberikan adalah menambah jumlah sampel sehingga hasil penelitian menjadi semakin valid, tidak menimbulkan bias sehingga dapat lebih menggambarkan pengaruh pemberian intervensi, menambah frekuensi pemberian intervensi sehingga hasil pemberian intervensi dapat maksimal.

\section{DAFTAR RUJUKAN}

Amirjani, N., Ashworth, N. L., Olson, J. L., Morhart, M., Chan, K. M. (2011). Validity and Reliability of The Purdue Pegboard Test in Carpal Tunnel Syndrome. Muscle and Nerve. 2(43). 171-177
Daniel, M. S. \& Strickland, L. R. 1992. Occupational Therapy Protocol Management in Adult Physical Dysfunction. Maryland: Aspen

Desai K., Kene, K., Doshi, M., More, S. (2005). Normative Data of Purdue Pegboard on Indian Population. The Indian Journal of Occupational Therapy. 3(37). 6972

Dyrkacz, A. P., Mak, L. Y. M. \& Heck, C. S. 2012. Work-Related Injuries in Canadian Occupational Therapy Practice. Canadian Journal of Occupational Therapy. 79(4). 237-247

Hagerott, J. J. 2012. Eastern Washington University Thesis Collections. Effect of Game Activities on Manual Dexterity in Older Adults. (34)

Metcalf, C. D., Irvine, T. A., Sims, J. L., Wang, Y. L., Su, A. W. Y., Norris, D. O. 2014. Complex Hand Dexterity: A Review of Biomechanical Methods for Measuring Musical Performance. Frontiers in Psychology. 5. 1-12

Mirzaie, M., Parsa, A., Salehi, M., Dahmardehei, M., Moghadam, M. H., Mirzaie, N.2014. Epidemiology of Hand Injuries in Children Presenting to an Orthopedic Trauma Center in Southeast of Iran. The Archives of Bone and Joint Surgery. 2(3). 225-231

Reed, K. L.2001. Quick Reference to Occupational Therapy. Maryland: Aspen

Stein, C. \& Yerxa, E. J., (1990). A Test of Fine Finger Dexterity. The American Journal of Occupational Therapy. 6(44). 499-504 
152 Jurnal Terpadu Ilmu Kesehatan, Volume 8, No 2, November 2019, hlm 130-219

Videler, A. J., Beelen, A., Schaik, I. N.

V., Visser M. D., Nollet, F.

(2008). Manual Dexterity in

Hereditary Motor and Sensory

Neuropathy Type 1A: Severity of

Limitations and Feasibility and

Reliability of Two Assessment

Instruments. Journal of

Rehabilitation Medicine.40.132-1 